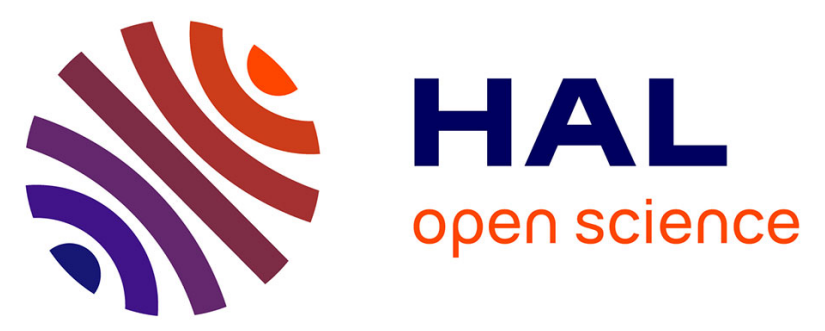

\title{
Adaptive AC Filter Parameters Identification for Voltage-Oriented Control of Three-Phase Voltage-Source Rectifiers, International Journal of Modelling
} Ali Bechouche, Hamid Seddiki, Djaffar Ould Abdeslam, Koussaila Mesbah

\section{- To cite this version:}

Ali Bechouche, Hamid Seddiki, Djaffar Ould Abdeslam, Koussaila Mesbah. Adaptive AC Filter Parameters Identification for Voltage-Oriented Control of Three-Phase Voltage-Source Rectifiers, International Journal of Modelling. International Journal of Modeling, Identification and Control (IJMIC), 2015, special issue on Formal Modeling and Verification of Critical Systems, 24 (4), pp.319331. 10.1504/IJMIC.2015.072985 . hal-01510362

\section{HAL Id: hal-01510362 \\ https://hal.science/hal-01510362}

Submitted on 19 Apr 2017

HAL is a multi-disciplinary open access archive for the deposit and dissemination of scientific research documents, whether they are published or not. The documents may come from teaching and research institutions in France or abroad, or from public or private research centers.
L'archive ouverte pluridisciplinaire HAL, est destinée au dépôt et à la diffusion de documents scientifiques de niveau recherche, publiés ou non, émanant des établissements d'enseignement et de recherche français ou étrangers, des laboratoires publics ou privés. 


\title{
Adaptive ac filter parameters identification for voltage- oriented control of three-phase voltage-source rectifiers
}

\section{Ali Bechouche and Hamid Seddiki}

L2CSP Laboratory,

Mouloud Mammeri University,

BP 17 RP Tizi-Ouzou, Algeria

E-mail: ali_bechouche@yahoo.fr

E-mail: sedikihamid2004@yahoo.fr

\section{Djaffar Ould Abdeslam*}

MIPS Laboratory,

University of Haute-Alsace,

4 rue des Frères Lumières, 68093 Mulhouse, France

E-mail: djaffar.ould-abdeslam@uha.fr

* Corresponding author

\section{Koussaila Mesbah}

L2CSP Laboratory,

Mouloud Mammeri University,

BP 17 RP Tizi-Ouzou, Algeria

E-mail: mesbahkoussaila@yahoo.fr

\begin{abstract}
This paper proposes an adaptive voltage-oriented control (VOC) with online ac filter parameters identification for three-phase voltage-source rectifier (VSR). A new method based on adaptive linear neuron (ADALINE) is first designed to identify the ac filter parameters. For accurate identification, the VSR nonlinearity are included in the ADALINE structure. Thereafter, the developed ADALINE is inserted in the VOC to realize an adaptive VOC. Thus, the decoupled terms and the proportional-integral current controller gains are updated online. Finally, the ADALINE ability to track properly the ac filter parameters is investigated by experimental analysis. It shows that the VSR nonlinearity consideration has significant influence on the resistance identification. Compared to the VOC, the enhancement of the proposed adaptive VOC is experimentally proved. The originality of this paper is the building of a VSR model including VSR nonlinearity that is suitable for implementation with ADALINE. This leads to ease implementation and accurate identification.
\end{abstract}

Kywords: Adaptive linear neuron, ac filter parameters, dead time analysis, decoupled terms, experimental investigation, identification, proportional-integral controller, voltage-oriented control, voltage-source rectifier (VSR), VSR nonlinearity.

Reference to this paper should be made as follows: Bechouche, A., Seddiki, H., Ould Abdeslam, D., and Mesbah K. (2015) 'Adaptive ac filter parameters identification for voltage-oriented control of three-phase voltage-source rectifiers', Int. J. Modelling, Identification and Control, Vol. xx, No. xx, pp. $\mathrm{xx}-\mathrm{xx}$.

Bibliographical notes: Ali Bechouche received Engineer, Magister, and Ph.D. degrees in electrical engineering from the Mouloud Mammeri University of Tizi-Ouzou, Tizi-Ouzou, Algeria, in 2007, 2009, and 2013, respectively. He is currently an Associate Professor in the Department of Electrical Engineering, Mouloud Mammeri University of Tizi-Ouzou. His research interests include electrical drives and advanced techniques applied to power electronics and wind energy conversion systems.

Hamid Seddiki received Engineer, Magister, and Ph.D. degrees in electrical engineering from the Mouloud Mammeri University of Tizi-Ouzou, Tizi-Ouzou, Algeria in 1991, 2000, and 2010, respectively. He received Accreditation to Supervise Research in electrical engineering from the Mouloud Mammeri University of Tizi-Ouzou in 2012. Since 1993, he has been with the Mouloud Mammeri University of Tizi-Ouzou, where he is currently an Associate Professor. His main interests include power electronics and electrical drives. 
Djaffar Ould Abdeslam received the M.Sc. degree in electrical engineering from the University of Franche-Comté, Besançon, France, in 2002 and Ph.D. degree from the University of Haute-Alsace, Mulhouse, France, in 2005. He is currently an Associate Professor in the University of HauteAlsace. His research interest includes artificial neural networks applied to power active filters and power electronics.

Koussaila Mesbah received the M.Sc. degree in electrical engineering from the Mouloud Mammeri University of Tizi-Ouzou, Tizi-Ouzou, Algeria, in 2011. He is currently a Ph.D. student at the Mouloud Mammeri University of Tizi-Ouzou. His main interests include electric machines and wind power generation.

\section{Introduction}

Three-phase voltage-source rectifiers (VSRs) are being increasingly used as high performance grid interface in power systems like distributed and renewable energy generation (Rashid, 2003). VSR offers several advantages in its operation such as bi-directional power flow, unity power factor (UPF), low harmonic distortion of input currents and high quality dc voltage (Rashid, 2003; Kolar and Friedli, 2013; Friedli et al., 2014).

The use of VSR requires incorporation of control system to achieve high performance. Voltage-oriented control (VOC) is the most classical method for VSR control (Rashid, 2003; Milasi et al., 2013; Antoniewicz and Kazmirkowski, 2008). This decoupled scheme, originally proposed in (Schauder and Mehta, 1993), uses two proportional-integral (PI) controllers in an inner loop to track current references and one PI controller in an outer loop to regulate dc voltage. Although the classical VOC has a simple structure, its robust performance to model uncertainties can be of concern (Malinowski et al., 2003). For instance, if the ac filter parameters are not known exactly, the $d$ - and $q$-axes current dynamics are not fully decoupled. Hence, the PI-based control scheme can be driven into instability (Shaker, 2014).

Several methods have been proposed as alternatives to classical VOC scheme. Researchers have developed direct power control which leads to direct control of active and reactive powers (Yan et al., 2014; Zhang et al., 2013; Norniella et al., 2011; Kwak et al., 2014). Control algorithms based on predictive approaches (Antoniewicz and Kazmirkowski, 2008; Zhang et al., 2013; Kwak et al., 2014; Xia et al. 2012; Ramirez et al., 2014; Korelic and Jezernik, 2013) and input-output feedback linearization approaches (Gensior et al., 2009; Burgos et al., 2005) have been also developed. Although the above-mentioned methods can provide improved performances, they suffer from their complexity or ease of tuning. This paper improves the classical VOC by means of an adaptive method for ac filter parameters identification.

The proper identification of ac filter parameters has a significant influence on correct operation of VSR control. However, this relevant subject has not let to a large number of specific studies. Some works propose a methods based on recursive least squares algorithm (Arriagada, 2003) and Lyapunov's function (Milasi et al., 2013) for inductance identification. Analytic and iterative methods are also presented in (Norniella et al., 2011) for inductance estimation. The two methods are based on the discontinuities that appear in estimated grid voltage when there is an error in the inductance estimation. In (Antoniewicz and Kazmirkowski, 2008), the inductance was estimated from average absolute values of VSR ac-side voltage and current. This method is simple, but second order low-pass filters are required to dismiss the high frequency variations associated with those magnitudes. Hence, the dynamic method is relatively slow, which leads to high inductance estimation error. Recently, a least square algorithm-based method is proposed in (Kwak et al., 2014) for adaptive resistance and inductance identification. Although the mentioned methods can provide acceptable results, some of them lead only to inductance estimation (Milasi et al., 2013; Antoniewicz and Kazmirkowski, 2008; Norniella et al., 2011; Arriagada, 2003 ) and, in low-power VSRs, the ac filter resistance cannot be neglected (Kwak et al., 2014). On the other hand, the used VSR terminal voltages in the identification process cannot be directly measured. They are usually estimated from output voltages of PI controllers and measured dc voltage. Since VSR nonlinearity due to the dead time and voltage drop exist in the used insulated-gate-bipolar-transistors (IGBTs) (Liu et al., 2012; Choi and Sul, 1996; Kim et al., 2006; Liu and Zhu, 2014), the mentioned methods (Milasi et al., 2013; Antoniewicz and Kazmirkowski, 2008; Norniella et al., 2011; Kwak et al., 2014; Arriagada, 2003) should operate without considering the VSR nonlinearity. Hence, the identified parameters may suffer from negligence of the VSR nonlinearity. Some authors have already studied the influence of voltage-source inverter nonlinearity on parameter estimation (Liu et al., 2012), and rotor flux linkage estimation (Liu and Zhu, 2014) in permanent-magnet synchronous machines. However, there is still no literature proposing a method for ac filter parameters identification of a VSR with VSR nonlinearity consideration.

In this paper, the proposed adaptive VOC maintains the simplicity of the classical VOC while providing robust performance to uncertainty in system parameters. A new method based on adaptive linear neuron (ADALINE) for ac filter parameters identification is first developed. The main advantage of this method is its simple structure, speed and ability to be trained online (Bechouche et al., 2012; Bechouche et al., 2014; Du et al., 2015). For accurate identification, the VSR nonlinearity is included in the ADALINE structure. Hence, correct ac filter parameters can be easily estimated online from the ADALINE weights. To guarantee the ADALINE's convergence, a discrete-time Lyapunov stability analysis (Romdhane et al., 2014) is presented. The proposed ADALINE identifier is 
experimented and the influence of VSR nonlinearity on the ac filter parameters identification is investigated. Thereafter, the identified parameters are used to perform an adaptive VOC where the decoupled terms and PI current controller gains are updated online. Finally, a comparative study showed the superiority of the proposed adaptive VOC scheme compared to the classical one under parameter uncertainties.

The paper is organized as follows. Section 2 presents the classical VOC of a VSR. The VSR nonlinearity is analyzed in Section 3. Section 4 presents the developed ADALINE identifier. Experimentation of the proposed adaptive VOC is given in Section 5. Finally, Section 6 concludes this paper.

\section{Classical VOC of a three-phase VSR}

\subsection{Three-phase VSR modeling}

The power circuit of the three-phase VSR is depicted in Figure 1. The VSR is connected to the grid through inductance $L$ and its serial resistance $R . e_{a}, e_{b}$, and $e_{c}$ are the balanced source voltages with their maximum amplitude $E$ and angular frequency $\omega ; i_{a}, i_{b}$, and $i_{c}$ are the input currents; $v_{a n}, v_{b n}$, and $v_{c n}$ are the VSR terminal voltages; $V_{d c}$ and $C$ are, respectively, the dc-link voltage and capacitance; $R_{L}$ is the load resistance. $S_{a}, S_{b}$, and $S_{c}$ stand for the switching state of each phase leg. $S_{i}=1$ ( $\left.i=a, b, c\right)$ means that the upper switch of phase $i$ is turned on, and the lower switch is turned off, while $\mathrm{S}_{i}=0$ denotes the opposite meaning. In this paper, $\mathrm{S}_{i}(i=\mathrm{a}, \mathrm{b}, \mathrm{c})$ are generated by a sinusoidal pulse-width modulation (SPWM) scheme. SPWM is based on comparing a triangular carrier wave with a three-phase modulation signals $\beta_{i}$ $(i=\mathrm{a}, \mathrm{b}, \mathrm{c})$. The phases of $\beta_{i}(i=\mathrm{a}, \mathrm{b}, \mathrm{c})$ are shifted by $2 \pi / 3$ and by $\varphi$ relative to the ac source. For three-phase VSR average model, $\mathrm{S}_{i}=\left(1+\beta_{i}\right) / 2(i=\mathrm{a}, \mathrm{b}, \mathrm{c})$ (Rashid, 2003). The modulation signals can be considered as a control inputs to the system and they are directly related to the amplitude and the phase of the VSR terminal voltages. The neutral of the ac sources is not connected. The resistance and the inductance of the feeder cables are neglected.

Figure 1 Topological structure of a three-phase VSR

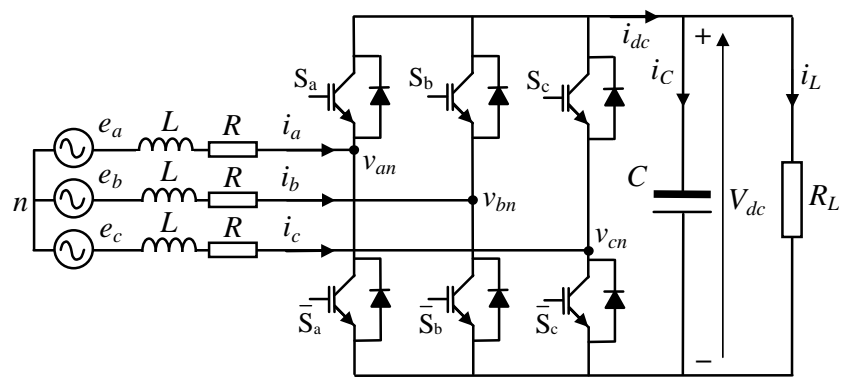

In $a b c$ coordinates, the three-phase VSR average model (Rashid, 2003) can be described as

$$
L \frac{d}{d t}\left[\begin{array}{l}
i_{a} \\
i_{b} \\
i_{c}
\end{array}\right]=\left[\begin{array}{ccc}
-R & 0 & 0 \\
0 & -R & 0 \\
0 & 0 & -R
\end{array}\right]\left[\begin{array}{l}
i_{a} \\
i_{b} \\
i_{c}
\end{array}\right]+\left[\begin{array}{l}
e_{a}-v_{a n} \\
e_{b}-v_{b n} \\
e_{c}-v_{c n}
\end{array}\right]
$$

$C \frac{d V_{d c}}{d t}=\frac{1}{2}\left(\beta_{a} i_{a}+\beta_{b} i_{b}+\beta_{c} i_{c}\right)-\frac{V_{d c}}{R_{L}}$

where

$\left[\begin{array}{c}v_{a n} \\ v_{b n} \\ v_{c n}\end{array}\right]=\frac{V_{d c}}{6}\left[\begin{array}{ccc}2 & -1 & -1 \\ -1 & 2 & -1 \\ -1 & -1 & 2\end{array}\right]\left[\begin{array}{c}\beta_{a} \\ \beta_{b} \\ \beta_{c}\end{array}\right]$

The VSR model (1) can be described in stationary $\alpha \beta$ frame, using Clark's transformation, as

$\left[\begin{array}{l}e_{\alpha} \\ e_{\beta}\end{array}\right]=L \frac{d}{d t}\left[\begin{array}{l}i_{\alpha} \\ i_{\beta}\end{array}\right]+\left[\begin{array}{cc}R & 0 \\ 0 & R\end{array}\right]\left[\begin{array}{l}i_{\alpha} \\ i_{\beta}\end{array}\right]+\left[\begin{array}{c}v_{\alpha n} \\ v_{\beta n}\end{array}\right]$

In Park's $d q$ frame, the model (4) can be reasonably represented by the following equations:

$\left[\begin{array}{l}e_{d} \\ e_{q}\end{array}\right]=L \frac{d}{d t}\left[\begin{array}{l}i_{d} \\ i_{q}\end{array}\right]+\left[\begin{array}{cc}R & -\omega L \\ \omega L & R\end{array}\right]\left[\begin{array}{l}i_{d} \\ i_{q}\end{array}\right]+\left[\begin{array}{l}v_{d n} \\ v_{q n}\end{array}\right]$

where $e_{d}, e_{q}, i_{d}$ and $i_{q}$ are, respectively, the $d$ - and $q$-axis components of the ac source voltages and the VSR input currents; $v_{d n}$ and $v_{q n}$ are the $d$ - and $q$-axis components of the VSR terminal voltages.

The dc voltage dynamics can be expressed by

$C \frac{d V_{d c}}{d t}+\frac{V_{d c}}{R_{L}}=\frac{3}{4}\left(i_{d} \beta_{d}+i_{q} \beta_{q}\right)$

where $\beta_{d}$ and $\beta_{q}$ are the $d$ - and $q$-axis components of the modulation signals.

The active $P$ and reactive $Q$ powers of the VSR are calculated as

$P=\frac{3}{2}\left(e_{d} i_{d}+e_{q} i_{q}\right) ; \quad Q=\frac{3}{2}\left(e_{q} i_{d}-e_{d} i_{q}\right)$

By setting the grid voltage vector according to the $d$-axis (i.e., $e_{d}=E$ and $e_{q}=0$ ), the equations (7.a) become

$P=\frac{3}{2} E i_{d} ; \quad Q=-\frac{3}{2} E i_{q}$

Under UPF operation $(Q=0)$, and according to (7.b), it can be deduced that $i_{q}$ is null $\left(i_{q}=0\right)$.

\subsection{Currents control}

In $d q$ frame, the currents controller controls the ac side currents to achieve UPF operation and constant dc voltage. As currents controller, the PI-type is usually used (Rashid, 2003; Malinowski et al., 2003). However, PI controller has no satisfactory tracking performance, especially, for the coupled system described in (5). So, for high performance application with accuracy current tracking, decoupled currents control scheme for VSR should be applied. The decoupled scheme is shown in Figure 2. From Figure 2, the expression (8) can be deduced where $K_{p c}$ and $K_{i c}$ are, respectively, proportional and integral gains of the PI controllers. $(\cdot)^{*}$ denotes a desired reference value. 
$\Delta v_{d}=K_{p c}\left(i_{d}^{*}-i_{d}\right)+\int K_{i c}\left(i_{d}^{*}-i_{d}\right) d t=L \frac{d i_{d}}{d t}+R i_{d}$

$\Delta v_{q}=K_{p c}\left(i_{q}^{*}-i_{q}\right)+\int K_{i c}\left(i_{q}^{*}-i_{q}\right) d t=L \frac{d i_{q}}{d t}+R i_{q}$

According to (8), under ideal decoupling between $d$ - and $q$-axes, the two axis currents can be independently controlled. For $K_{p c}$ and $K_{i c}$ synthesis, a pole compensation method can be applied. Therefore, PI gains are designed as $K_{p c}=3 L / t_{r}$ and $K_{i c}=3 R / t_{r}$, where $t_{r}$ is the desired time response.

Figure 2 Decoupled currents control of three-phase VSR

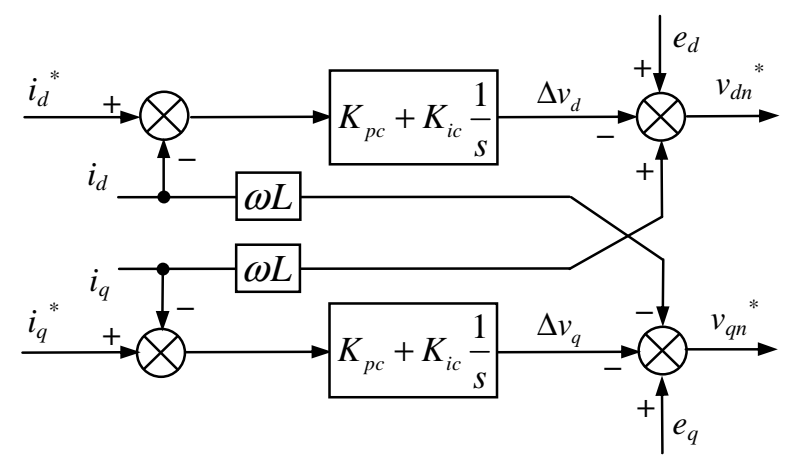

\section{3 dc voltage regulation}

In designing the controller of the dc voltage dynamics, it is assumed that dc voltage varies on a time scale significantly slower than the $d$-axis current. Hence, the current $i_{d}$ tracks perfectly its reference $i_{d}{ }^{*}$. The dc voltage control scheme is reported in Figure 3 where $K_{p v}$ and $K_{i v}$ are, respectively, proportional and integral gains of the voltage PI controller. From Figure 3, the equation (9) can be deduced. The gains $K_{p v}$ and $K_{i v}$ are designed using a pole placement method as $K_{p v}=2 z_{0 v} C \omega_{0 v}$ and $K_{i v}=C \omega_{0 v}{ }^{2}$ where $z_{0 v}$ is the damping ratio and $\omega_{0 v}$ is the undamped natural frequency of the controlled system in closed-loop.

$i_{C}^{*}=K_{p v}\left(V_{d c}^{*}-V_{d c}\right)+\int K_{i v}\left(V_{d c}^{*}-V_{d c}\right) d t=C \frac{d V_{d c}}{d t}$

Once the VSR model and classical VOC are presented, the following section will analyze the VSR nonlinearity due to voltage drop and dead time effects in the used IGBTs.

Figure 3 dc voltage regulation of three-phase VSR

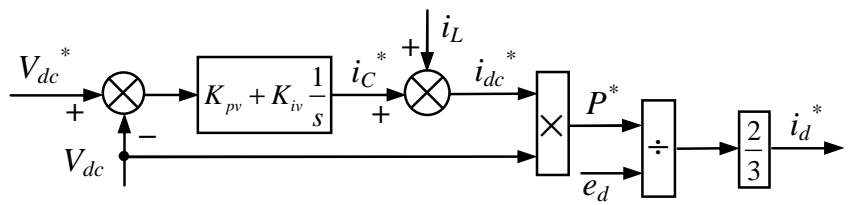

\section{Nonlinearity analysis of three-phase VSR}

Figure 4 shows the nonlinearity for one leg of three-phase VSR, including two IGBTs. As can be seen in this figure, if $i_{a}$ flows to load $\left(i_{a}>0\right)$, the actual phase to center voltage $v_{a o}$ is $v_{a o}=\frac{V_{d c}}{2}+V_{d} \quad\left(\right.$ when $\left.\mathrm{S}_{\mathrm{a}}=1\right)$

$v_{a o}=-\frac{V_{d c}}{2}+V_{c e} \quad\left(\right.$ when $\left.\mathrm{S}_{\mathrm{a}}=0\right)$

where $V_{c e}$ and $V_{d}$ are, respectively, the voltage drops of the active switch and freewheeling diode. If $i_{a}$ flows from load $\left(i_{a}<0\right)$, the actual phase to center voltage $v_{a o}$ is calculated as

$\begin{array}{ll}v_{a o}=\frac{V_{d c}}{2}-V_{c e} & \left(\text { when } \mathrm{S}_{\mathrm{a}}=1\right) \\ v_{a o}=-\frac{V_{d c}}{2}-V_{d} & \left(\text { when } \mathrm{S}_{\mathrm{a}}=0\right)\end{array}$

Therefore, $v_{a o}$ can be represented in a general form as

$v_{a o}=\left(V_{d c}-V_{c e}+V_{d}\right)\left(\mathrm{S}_{\mathrm{a}}-\frac{1}{2}\right)+\frac{1}{2} \operatorname{sign}\left(i_{a}\right)\left(V_{c e}+V_{d}\right)$

where, $\operatorname{sign}\left(i_{a}\right)=\left\{+1\right.$ if $i_{a}>0 ;-1$ if $\left.i_{a}<0\right\}$.

In many cases, the voltage drops in the IGBT increase with current. Thus, they can be represented as follows (Choi and Sul, 1996):

$V_{c e}=V_{c e 0}+r_{c e}\left|i_{a}\right|, \quad V_{d}=V_{d 0}+r_{d}\left|i_{a}\right|$

where $V_{c e 0}$ and $V_{d 0}$ are, respectively, the threshold voltages of active switch and freewheeling diode. $r_{c e}$ and $r_{d}$ are, respectively, the equivalent resistances of active switch and freewheeling diode.

By substituting (13) in (12), $v_{a o}$ is rewritten as follows:

$$
\begin{aligned}
v_{a o}= & \left(V_{d c}-V_{c e}+V_{d}\right)\left(\mathrm{S}_{\mathrm{a}}-\frac{1}{2}\right)+\frac{1}{2} \operatorname{sign}\left(i_{a}\right)\left(V_{c e 0}+V_{d 0}\right) \\
& +\frac{1}{2}\left(r_{c e}+r_{d}\right) i_{a}
\end{aligned}
$$

From (14), the average phase to center voltage can be derived as

$$
\begin{aligned}
v_{a o}= & \left(V_{d c}-V_{c e}+V_{d}\right)\left(\frac{T_{a}}{T_{\mathrm{sw}}}-\frac{1}{2}\right)+\frac{1}{2} \operatorname{sign}\left(i_{a}\right)\left(V_{c e 0}+V_{d 0}\right) \\
& +\frac{1}{2}\left(r_{c e}+r_{d}\right) i_{a}
\end{aligned}
$$

where $T_{a}$ and $T_{s w}$ are, respectively, the effective time duration and the SPWM carrier period. Similarly, the average phase to center voltage of other phases can be obtained as follows:

$$
\begin{aligned}
v_{b o}= & \left(V_{d c}-V_{c e}+V_{d}\right)\left(\frac{T_{b}}{T_{\mathrm{sw}}}-\frac{1}{2}\right)+\frac{1}{2} \operatorname{sign}\left(i_{b}\right)\left(V_{c e 0}+V_{d 0}\right) \\
& +\frac{1}{2}\left(r_{c e}+r_{d}\right) i_{b} \\
v_{c o}= & \left(V_{d c}-V_{c e}+V_{d}\right)\left(\frac{T_{c}}{T_{\mathrm{sw}}}-\frac{1}{2}\right)+\frac{1}{2} \operatorname{sign}\left(i_{c}\right)\left(V_{c e 0}+V_{d 0}\right) \\
& +\frac{1}{2}\left(r_{c e}+r_{d}\right) i_{c}
\end{aligned}
$$


where $T_{b}$ and $T_{c}$ are the effective time duration of phases $b$ and $c$, respectively.

Figure 4 Nonlinearity for one leg of three-phase VSR

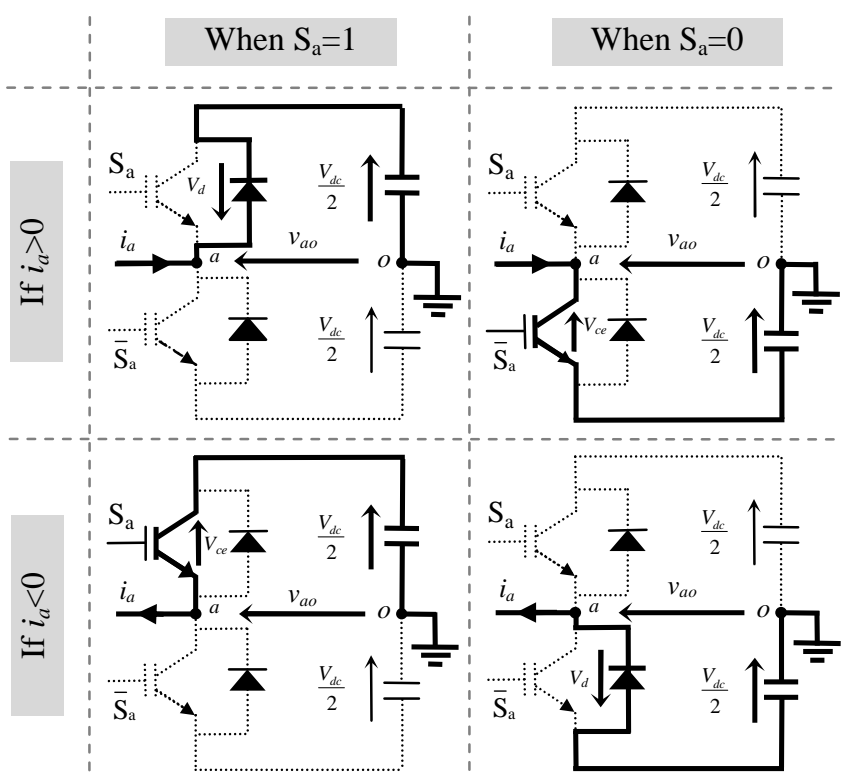

On the other hand, to turn on and turn off the active switches in the VSR, the gate drive signals are needed. The ideal switching states are shown in Figure 5(a). The commanded time duration $T_{a}{ }^{*}$ is the area between $t_{1}$ and $t_{2}$. The practical switching states including a dead time $T_{d}$ are represented in Figure 5(b). These signals are delayed with $T_{d}$ from the ideal switching states. The actual phase to center voltage $v_{a o}$, considering the dead time, turn-on delay time $T_{\text {on }}$ and turn-off delay time $T_{\text {off }}$ of the switches, is illustrated in Figure 5(c) for $i_{a}>0$ and in Figure 5(d) for $i_{a}<0$. The effective time duration $T_{a}$ is the area between $t_{5}$ and $t_{6}$ for $i_{a}>0$ or between $t_{3}$ and $t_{4}$ for $i_{a}<0$. From Figures 5(a)-(d), the time error $T_{a \text { err }}$ (Kim et al., 2006) can be deduced as

$T_{a \mathrm{err}}=T_{a}-T_{a}^{*}=T_{a}-\left(t_{2}-t_{1}\right)$

When $i_{a}$ is positive, $T_{a \text { err }}=T_{d}+T_{\text {on }}-T_{\text {off }}$ and when $i_{a}$ is negative, $T_{a \text { err }}=-\left(T_{d}+T_{\text {on }}-T_{\text {off }}\right)$. The time error can be represented as

$T_{a \mathrm{err}}=\operatorname{sign}\left(i_{a}\right)\left(T_{d}+T_{\mathrm{on}}-T_{\text {off }}\right)$

From (16) and (17), the effective time duration can be deduced as

$T_{a}=T_{a}^{*}+\operatorname{sign}\left(i_{a}\right) M$

where $M=T_{d}+T_{\text {on }}-T_{\text {off }}$.

Similarly, the effective time duration of phases $b$ and $c$ can be deduced as follows:

$$
\begin{aligned}
& T_{b}=T_{b}^{*}+\operatorname{sign}\left(i_{b}\right) M \\
& T_{c}=T_{c}^{*}+\operatorname{sign}\left(i_{c}\right) M
\end{aligned}
$$

To calculate the VSR average terminal voltages including the nonlinearity, the knowledge of the relationship between the terminal voltage and the phase to center voltage is required. This relationship can be written as follows:

$\left[\begin{array}{l}v_{a o} \\ v_{b o} \\ v_{c o}\end{array}\right]=\left[\begin{array}{l}v_{a n} \\ v_{b n} \\ v_{c n}\end{array}\right]+\left[\begin{array}{l}v_{n o} \\ v_{n o} \\ v_{n o}\end{array}\right]$

The absence of a neutral connection in the ac source forces the constraint that

$i_{a}+i_{b}+i_{c}=0$

For any balanced ac filter parameters and grid voltages, the terminal voltages are constrained such that

$v_{a n}+v_{b n}+v_{c n}=0$

From (19) and (21), the neutral to center voltage becomes

$v_{n o}=\frac{1}{3}\left(v_{a o}+v_{b o}+v_{c o}\right)$

Therefore, the relationship between the terminal voltage and the phase to centre voltage can be deduced as follows:

$\left[\begin{array}{l}v_{a n} \\ v_{b n} \\ v_{b n}\end{array}\right]=\frac{1}{3}\left[\begin{array}{ccc}2 & -1 & -1 \\ -1 & 2 & -1 \\ -1 & -1 & 2\end{array}\right]\left[\begin{array}{l}v_{a o} \\ v_{b o} \\ v_{c o}\end{array}\right]$

For phase $a$, the average terminal voltage including VSR nonlinearity can be calculated from (15), (18) and (23) as

$$
\begin{aligned}
v_{a n}= & \frac{1}{3}\left(V_{d c}-V_{c e}+V_{d}\right)\left(\frac{2 T_{a}^{*}-T_{b}^{*}-T_{c}^{*}}{T_{\mathrm{sw}}}\right) \\
& +\frac{1}{6}\left(\left(V_{d c}-V_{c e}+V_{d}\right) \frac{2 M}{T_{\mathrm{sw}}}+V_{c e 0}+V_{d 0}\right) \\
& \times\left(2 \operatorname{sign}\left(i_{a}\right)-\operatorname{sign}\left(i_{b}\right)-\operatorname{sign}\left(i_{c}\right)\right)+\frac{1}{2}\left(r_{c e}+r_{d}\right) i_{a}
\end{aligned}
$$

In (24), the term $V_{c e}-V_{d}$ is neglected because $V_{d c}$ is much greater than $V_{c e}-V_{d}$ (Choi and Sul, 1996). Hence, (24) is simplified as

$$
\begin{aligned}
v_{a n}= & \frac{V_{d c}}{3 T_{\mathrm{sw}}}\left(2 T_{a}^{*}-T_{b}^{*}-T_{c}^{*}\right)+\frac{1}{6}\left(\frac{2 M V_{d c}}{T_{\mathrm{sw}}}+V_{c e 0}+V_{d 0}\right) \\
& \times\left(2 \operatorname{sign}\left(i_{a}\right)-\operatorname{sign}\left(i_{b}\right)-\operatorname{sign}\left(i_{c}\right)\right)+\frac{1}{2}\left(r_{c e}+r_{d}\right) i_{a}
\end{aligned}
$$

Similarly, the average terminal voltage including VSR nonlinearity of phase $b$ and $c$ can be easily deduced. Hence, the average terminal voltage vector is represented in the following matrix form:

$$
\left[\begin{array}{l}
v_{a n} \\
v_{b n} \\
v_{c n}
\end{array}\right]=\left[\begin{array}{c}
v_{a n}^{*} \\
v_{b n}^{*} \\
v_{c n}^{*}
\end{array}\right]+V_{\text {dist }}\left[\begin{array}{l}
D_{a} \\
D_{b} \\
D_{c}
\end{array}\right]+\frac{1}{2}\left(r_{c e}+r_{d}\right)\left[\begin{array}{l}
i_{a} \\
i_{b} \\
i_{c}
\end{array}\right]
$$


where

$$
\begin{aligned}
& {\left[\begin{array}{c}
v_{a n}^{*} \\
v_{b n}^{*} \\
v_{c n}^{*}
\end{array}\right]=\frac{V_{d c}}{3 T_{\mathrm{sw}}}\left[\begin{array}{ccc}
2 & -1 & -1 \\
-1 & 2 & -1 \\
-1 & -1 & 2
\end{array}\right]\left[\begin{array}{c}
T_{a}^{*} \\
T_{b}^{*} \\
T_{c}^{*}
\end{array}\right]} \\
& V_{\mathrm{dist}}=\frac{1}{6}\left(\frac{2 M V_{d c}}{T_{\mathrm{sw}}}+V_{c e 0}+V_{d 0}\right) \\
& {\left[\begin{array}{l}
D_{a} \\
D_{b} \\
D_{c}
\end{array}\right]=\left[\begin{array}{l}
2 \operatorname{sign}\left(i_{a}\right)-\operatorname{sign}\left(i_{b}\right)-\operatorname{sign}\left(i_{c}\right) \\
-\operatorname{sign}\left(i_{a}\right)+2 \operatorname{sign}\left(i_{b}\right)-\operatorname{sign}\left(i_{c}\right) \\
-\operatorname{sign}\left(i_{a}\right)-\operatorname{sign}\left(i_{b}\right)+2 \operatorname{sign}\left(i_{c}\right)
\end{array}\right]}
\end{aligned}
$$

Therefore, the VSR model including nonlinearity is derived by substituting (26) in (1). In the next section, the VSR nonlinearity will be included in the ADALINE structure for accurately identifying $R$ and $L$ values.

Figure 5 VSR input voltage and IGBT drive signals: (a) ideal IGBT drive signal, (b) actual drive signal with dead time, (c) actual output voltage with dead time and switch-on/switch-off times for $i_{a}>0$, (d) actual output voltage with dead time and switch-on/switch-off times for $i_{a}<0$

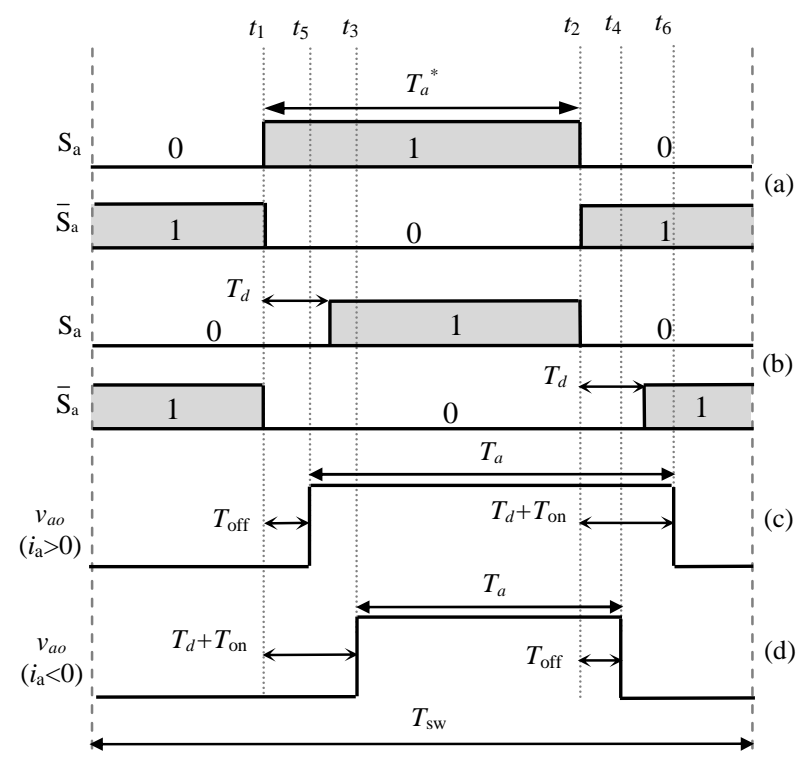

\section{Adaptive VOC of three-phase VSR}

In this section, the ADALINE is first designed for $R$ and $L$ identification. Then, stability condition of the proposed ADALINE identifier is established. At last, overall structure of the developed adaptive VOC of a VSR is illustrated and discussed.

\subsection{ADALINE for $R$ and L identification}

In stationary $\alpha \beta$ frame, the equation (26) can be expressed as follows:

$\left[\begin{array}{c}v_{\alpha n} \\ v_{\beta n}\end{array}\right]=\left[\begin{array}{c}v_{\alpha n}^{*} \\ v_{\beta n}^{*}\end{array}\right]+V_{\text {dist }}\left[\begin{array}{c}D_{\alpha} \\ D_{\beta}\end{array}\right]+\frac{1}{2}\left(r_{c e}+r_{d}\right)\left[\begin{array}{c}i_{\alpha} \\ i_{\beta}\end{array}\right]$ where

$\left[\begin{array}{c}D_{\alpha} \\ D_{\beta}\end{array}\right]=\left[\begin{array}{c}2 \operatorname{sign}\left(i_{a}\right)-\operatorname{sign}\left(i_{b}\right)-\operatorname{sign}\left(i_{c}\right) \\ \sqrt{3} \operatorname{sign}\left(i_{b}\right)-\sqrt{3} \operatorname{sign}\left(i_{c}\right)\end{array}\right]$

By substituting (28.a) in (4), the $\alpha$-axis dynamic model of the VSR can be selected as follows:

$e_{\alpha}=L \frac{d i_{\alpha}}{d t}+R i_{\alpha}+v_{\alpha n}^{*}+V_{\text {dist }} D_{\alpha}+\frac{1}{2}\left(r_{c e}+r_{d}\right) i_{\alpha}$

and (29) can be rewritten under the following form:

$Z_{\alpha}=L \frac{d i_{\alpha}}{d t}+R i_{\alpha}+V_{\text {dist }} D_{\alpha}$

where

$Z_{\alpha}=e_{\alpha}-v_{\alpha n}^{*}-\frac{1}{2}\left(r_{c e}+r_{d}\right) i_{\alpha}$

Using the Euler approximation with a sampling period $T_{s}$, the derivative of $i_{\alpha}$ is approximated as

$\frac{d i_{\alpha}}{d t} \approx \frac{i_{\alpha}(k+1)-i_{\alpha}(k)}{T_{s}}$

Then, $i_{\alpha}$ is represented in the discrete-time domain as

$i_{\alpha}(k)=\mathrm{A} \cdot Z_{\alpha}(k-1)+\mathrm{B} \cdot i_{\alpha}(k-1)+\mathrm{C} \cdot D_{\alpha}(k-1)$

where

$Z_{\alpha}(k-1)=e_{\alpha}(k-1)-v_{\alpha n}^{*}(k-1)-\frac{1}{2}\left(r_{c e}+r_{d}\right) i_{\alpha}(k-1)$,

$\mathrm{A}=\frac{T_{s}}{L}, \mathrm{~B}=1-\frac{R T_{s}}{L}, \mathrm{C}=-\frac{T_{s}}{L} V_{\text {dist }}$.

Therefore, the quantities $R, L$ and $V_{\text {dist }}$ can be deduced from (32) in the following way:

$L=\frac{T_{s}}{\mathrm{~A}} ; R=\frac{1-\mathrm{B}}{\mathrm{A}} ; V_{\mathrm{dist}}=-\frac{\mathrm{C}}{\mathrm{A}}$.

According to (32.a), the coefficients A, B, C can be easily identified online by three weights $\mathrm{W}_{1}, \mathrm{~W}_{2}$ and $\mathrm{W}_{3}$ of the ADALINE. Indeed, by choosing the ADALINE with three inputs $Z_{\alpha}(k-1), i_{\alpha}(k-1)$ and $D_{\alpha}(k-1)$, the estimated $\alpha$-axis current dynamics $\hat{i}_{\alpha}(k)$ can be computed as

$\hat{i}_{\alpha}(k)=\mathrm{W}_{1} \cdot Z_{\alpha}(k-1)+\mathrm{W}_{2} \cdot i_{\alpha}(k-1)+\mathrm{W}_{3} \cdot D_{\alpha}(k-1)$

or in vectorial form

$\hat{i}_{\alpha}(k)=\mathrm{W}(k) \cdot X_{\alpha}(k-1)$

where $X_{\alpha}(k-1)=\left[\begin{array}{lll}Z_{\alpha}(k-1) & i_{\alpha}(k-1) & D_{\alpha}(k-1)\end{array}\right]^{T}$ and $\mathrm{W}(k)=$ $\left[\mathrm{W}_{1}(k) \mathrm{W}_{2}(k) \mathrm{W}_{3}(k)\right]$ are, respectively, the input vector and the weights vector of the ADALINE. $\left({ }^{\wedge}\right)$ indicates the estimated quantities.

When $i_{\alpha}(k)$ is well estimated, the equality given by (35) is satisfied, with $Y(k)=[\mathrm{A}(k) \mathrm{B}(k) \mathrm{C}(k)]$.

$\mathrm{W}(k)=Y(k)$. 
Hence, from (33) and (35), the parameters $R, L$ and $V_{\text {dist }}$ are finally identified in the following way:

$\hat{L}=\frac{T_{s}}{\mathrm{~W}_{1}} ; \quad \hat{R}=\frac{1-\mathrm{W}_{2}}{\mathrm{~W}_{1}} ; \quad \hat{V}_{\text {dist }}=-\frac{\mathrm{W}_{3}}{\mathrm{~W}_{1}}$

Figure 6 ADALINE structure for ac filter parameters identification

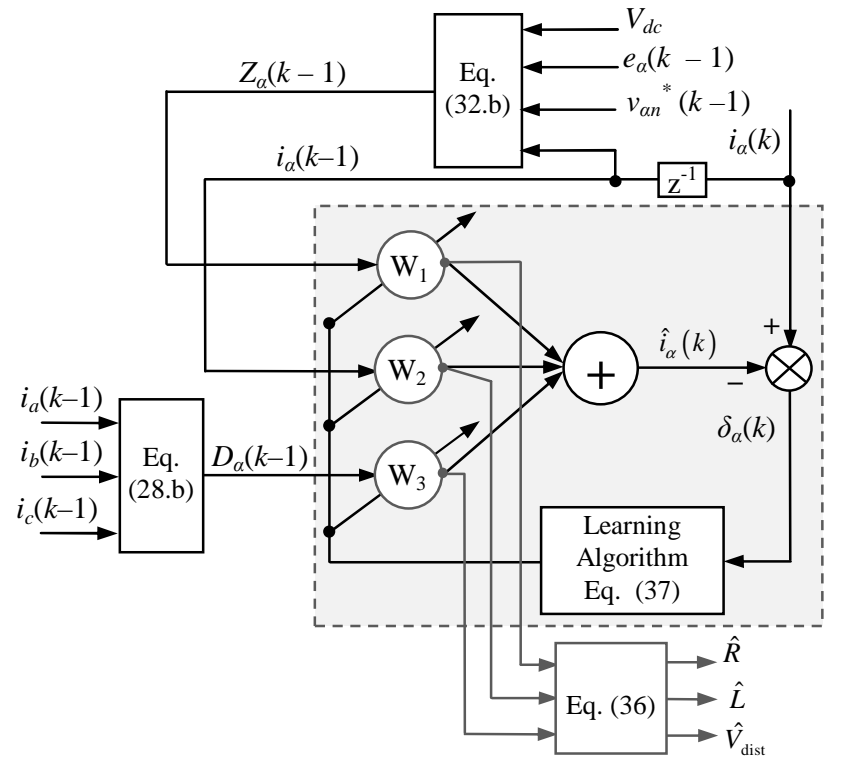

The topology shown in Figure 6 represents the identification process of $R, L$ and $V_{\text {dist }}$ using ADALINE technique. This topology has the natural dynamic characteristics of the current $i_{\alpha}$ dynamics. Therefore, the stability of the proposed method can be verified with an appropriate weight vector adaptation using the estimation error (Romdhane et al., 2014). This method has high immunity to measurement noise, because the feedback is used only in the weight adaptation algorithm (Bechouche et al., 2012; Du et al., 2015). In this paper, $V_{\text {dist }}$ is identified just for the validation of identification algorithm and does not used in VOC. Indeed, $V_{\text {dist }}$ can indicate the convergence quality of ADALINE weights.

Using (34), the current estimation error $\delta_{\alpha}(k)=i_{\alpha}(k)-\hat{i}_{\alpha}(k)$ will be produced due to any mismatch between the estimated current and the actual one. This error is produced namely by parameter variation. Accordingly, it can be used to adaptively adjust the weight vector $\mathrm{W}(k)=$ $\left[\mathrm{W}_{1}(k) \mathrm{W}_{2}(k) \mathrm{W}_{3}(k)\right]$ in a manner that minimizes the error. To achieve this objective, a least mean square algorithm with learning rate $\eta$ is used for the weights updating (Bechouche et al., 2012; Du et al., 2015). Then, the ADALINE weight vector $\mathrm{W}(k)$ is recursively updated as follows:

$$
\mathrm{W}(k+1)=\mathrm{W}(k)+\frac{\eta \delta_{\alpha}(k) X_{\alpha}(k-1)}{\varepsilon+X_{\alpha}^{T}(k-1) X_{\alpha}(k-1)}
$$

where $\eta$ is the learning rate and $\varepsilon$ is a small value to avoid division by zero if $X_{\alpha}^{\mathrm{T}}(k-1) X_{\alpha}(k-1)=0$.

Figure 7 Proposed scheme for adaptive VOC of a VSR with online ac filter parameters identification

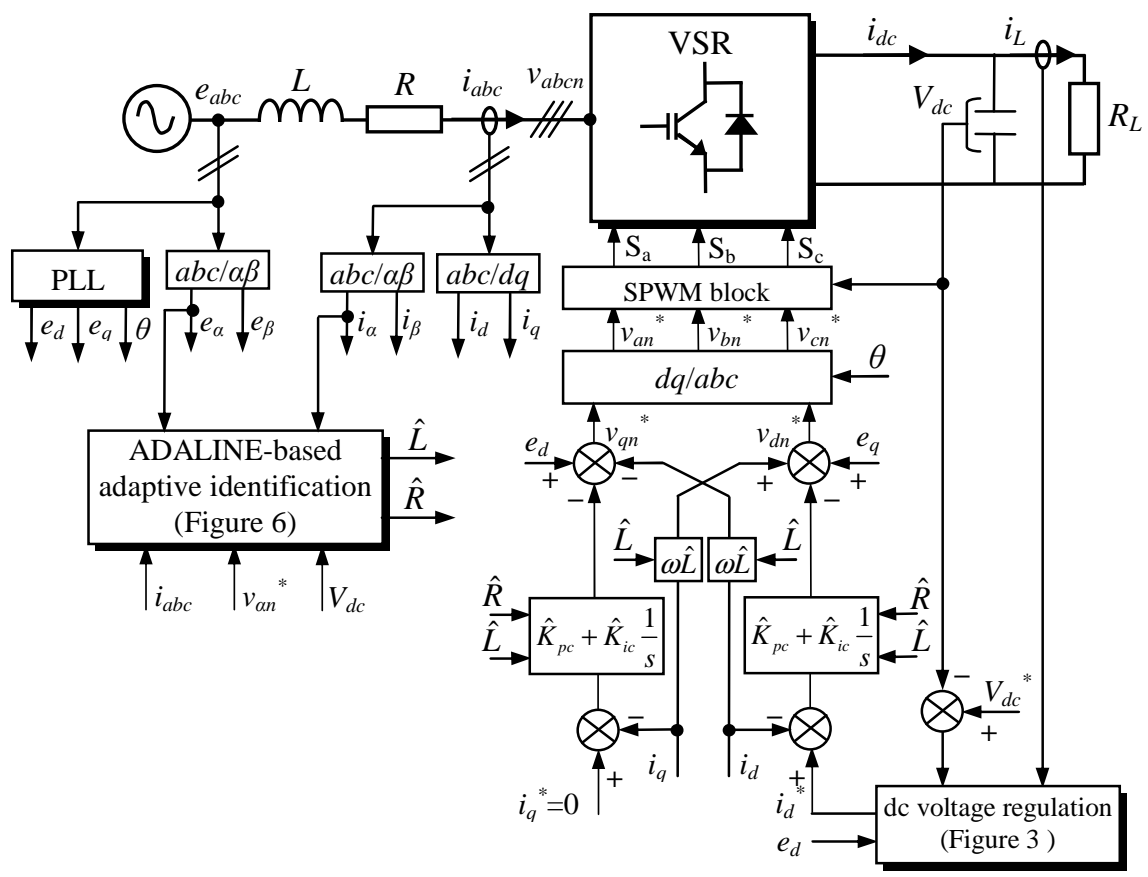




\subsection{Stability analysis of the ADALINE identifier}

To prove the stability of the ADALINE identifier and to give the guideline in tuning the learning rate parameter $\eta$, Lyapunov function candidate for the parameter identifier (37) is used (Romdhane et al., 2014). This function is selected as

$V(k)=\tilde{\mathrm{W}}^{T}(k) \tilde{\mathrm{W}}(k)$

where $\tilde{\mathrm{W}}(k)$ is the ADALINE estimation error, defined as

$\tilde{\mathrm{W}}(k) \equiv Y(k)-\mathrm{W}(k)$

The Lyapunov's convergence criterion must be satisfied such that

$V(k) \Delta V(k)<0$

where $\Delta V(k)$ is the change in the Lyapunov function. As $\Delta V(k)$ is defined positive as shown in (38), the stability condition (40) is satisfied when $\Delta V(k)<0$. The change in Lyapunov function is given by

$$
\Delta V(k)=V(\tilde{\mathrm{W}}(k+1))-V(\tilde{\mathrm{W}}(k))<0
$$

By using the parameters identifier error dynamics, which can be derived from (39), with the update law (37), $\Delta V(k)$ can be evaluated as

$$
\begin{aligned}
\Delta V(k) & =\left\|\tilde{\mathrm{W}}(k)-\frac{\eta X_{\alpha}^{T}(k-1) X_{\alpha}^{T}(k-1) \tilde{\mathrm{W}}(k)}{\varepsilon+X_{\alpha}^{T}(k-1) X_{\alpha}(k-1)}\right\|^{2}-\tilde{\mathrm{W}}^{T}(k) \tilde{\mathrm{W}}(k) \\
& =\frac{\eta\left[\tilde{\mathrm{W}}(k) X_{\alpha}(k-1)\right]^{2}}{\varepsilon+X_{\alpha}^{T}(k-1) X_{\alpha}(k-1)}\left[-2+\frac{\eta X_{\alpha}^{T}(k-1) X_{\alpha}(k-1)}{\varepsilon+X_{\alpha}^{T}(k-1) X_{\alpha}(k-1)}\right]
\end{aligned}
$$

where $\|\cdot\|$ is the Euclidian norm in $\Re^{n}$. Assuming that $\varepsilon>0$ and $0<\eta<2$, the bracketed term in (42) is negative and consequently the stability condition in (41) is satisfied. The following convergence properties are also satisfied:

$$
\begin{aligned}
& \left\|\mathrm{W}(k)-\mathrm{W}_{0}\right\| \leq\left\|\mathrm{W}(k-1)-\mathrm{W}_{0}\right\| \leq\left\|\mathrm{W}(0)-\mathrm{W}_{0}\right\|, k \geq 1 \\
& \lim _{k \rightarrow \infty} \frac{\tilde{\mathrm{W}}(k) X_{\alpha}(k-1)}{\sqrt{\varepsilon+X_{\alpha}(k-1)^{T} X_{\alpha}(k-1)}}=0
\end{aligned}
$$

where $\mathrm{W}_{0}$ is the vector obtained at perfect convergence of the estimator. According to (43), the augmented error is monotonically non-increasing, hence, the convergence is guaranteed.

\subsection{Adaptive VOC of a VSR}

In classical VOC, the current dynamics in $d q$ frame is decoupled. The decoupling scheme requires an accurate knowledge of $L$. Hence, if $L$ is not known, the current dynamics will not be decoupled perfectly. Although the integral term in the PI controller compensates for steady-state coupling disturbances, the transient system performance will be degraded (Milasi et al., 2013). In addition, stability of the inner currents control is mainly affected by parameter uncertainties (Shaker, 2014). As shown in Section 2.2, $K_{p c}$ and $K_{i c}$ are directly designed from the identified $R$ and $L$ values. Therefore, with uncertainties in $R$ and $L$, the currents control performances will be degraded and the system can be driven into instability (Milasi et al., 2013). To overcome this, an adaptive VOC scheme is proposed. Figure 7 shows the overall structure of the developed adaptive VOC of a VSR with online $R$ and $L$ identification. As $R$ and $L$ are updated online while the VSR runs, the proposed scheme guarantees asymptotic decoupling of the current error dynamics and stability of the PI currents controllers. As VOC strategy requires a phase-locked loop (PLL) for grid synchronization, an adaptive neural PLL is used (Bechouche et al., 2014). Note that the proposed adaptive VOC scheme can be implemented without any additional sensors compared to those already used in the classical scheme.

To validate in experiment the suggested ADALINE identifier and adaptive VOC strategy, the following section will present the experimental investigation.

\section{Experimental investigation}

The hardware platform of the three-phase VSR is first introduced. Then, the developed ADALINE-based algorithm for $R, L$ and $V_{\text {dist }}$ identification is tested. At last, the identified $R$ and $L$ are used to perform an adaptive VOC of the VSR.

Figure 8 Different parts of the experimental platform: 1) threephase VSR, 2) PC-Pentium + dSPACE board, 3) dSPACE I/O connectors, 4) isolating transformer, 5) interconnecting resistances and inductances, 6) voltage sensors, 7) current sensors, 8) load resistance

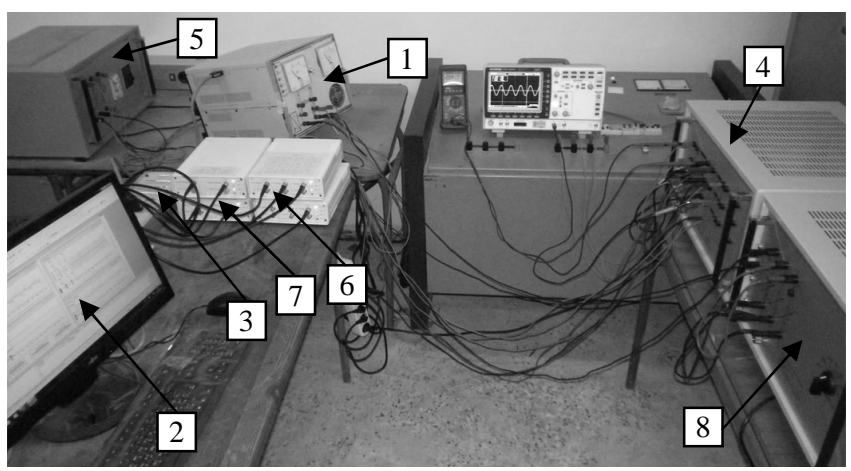

Table 1 Control and power circuit parameters of a VSR

\begin{tabular}{lc}
\hline PWM frequency $f_{s w}(\mathrm{kHz})$ & 7.5 \\
Nominal resistance of ac filter $R(\Omega)$ & 1 \\
Nominal inductance of ac filter $L(\mathrm{mH})$ & 10 \\
dc-bus capacitor $C(\mathrm{mF})$ & 3.3 \\
Nominal load resistance $R_{L}(\Omega)$ & 40 \\
Supply phase voltage RMS $(\mathrm{V})$ & 45 \\
Supply voltage frequency $f(\mathrm{~Hz})$ & 50 \\
Nominal dc-bus voltage $V_{d c}(\mathrm{~V})$ & 150 \\
\hline
\end{tabular}

\subsection{Experimental platform description}

The developed adaptive VOC strategy is tested in a threephase VSR. The specifications of the experimental system 
are given in Table 1 while the test bench is shown in Figure 8. It consists of a three-phase IGBT based VSR of $120 \mathrm{kVA}$ (Mitsubishi) with anti-paralleling diodes (module CM100DY-24H). Three Hall-effect voltage sensors of LV25$P$ type and three Hall-effect current sensors of LA55-P type are used to measure dc-bus voltage $V_{d c}$, two grid voltages $\left(e_{a}\right.$, and $e_{b}$ ), two input currents $\left(i_{a}\right.$ and $\left.i_{b}\right)$ and load current $i_{L}$, respectively.

Table 2 Typical electrical characteristics of the used IGBT modules (from Mitsubishi CM100DY-24H datasheet)

\begin{tabular}{lc}
\hline Turn-on delay time $T_{\text {on }}(\mu \mathrm{s})$ & 0.1 \\
Turn-off delay time $T_{\text {off }}(\mu \mathrm{s})$ & 0.3 \\
Switching control dead time $T_{d}(\mu \mathrm{s})$ & 3.5 \\
Threshold voltage of the active switch $V_{c e 0}(\mathrm{~V})$ & 0.8 \\
Threshold voltage of the freewheeling diode $V_{d 0}(\mathrm{~V})$ & 0.7 \\
Equivalent resistance of the active switch $r_{c e}(\mathrm{~m} \Omega)$ & 9.4 \\
Equivalent resistance of the freewheeling diode $r_{d}(\mathrm{~m} \Omega)$ & 15 \\
\hline
\end{tabular}

To test experimentally the developed identification and control method, a DS1104 dSPACE board based on TMS320F240 is used. The algorithms are programmed in MATLAB/Simulink environment and implemented using Euler resolution method and sampling period of $250 \mu \mathrm{s}$. Simulink's Real-Time Workshop is used to build real time code and execute it on dSPACE hardware inserted in a PCPentium. Slave DSP three-phase PWM generation block is used to convert modulation signals $\left(\beta_{a}, \beta_{b}\right.$ and $\left.\beta_{c}\right)$ provided by SPWM to PWM signals $S_{a}, S_{b}$ and $S_{c}$. The ADALINE identifier is implemented with a learning rate $\eta=0.01$. This value is experimentally adjusted to ensure stability and optimal speed of weights convergence.

Figure 9 Used signals in identification of $R, L$ and $V_{\text {dist }}$

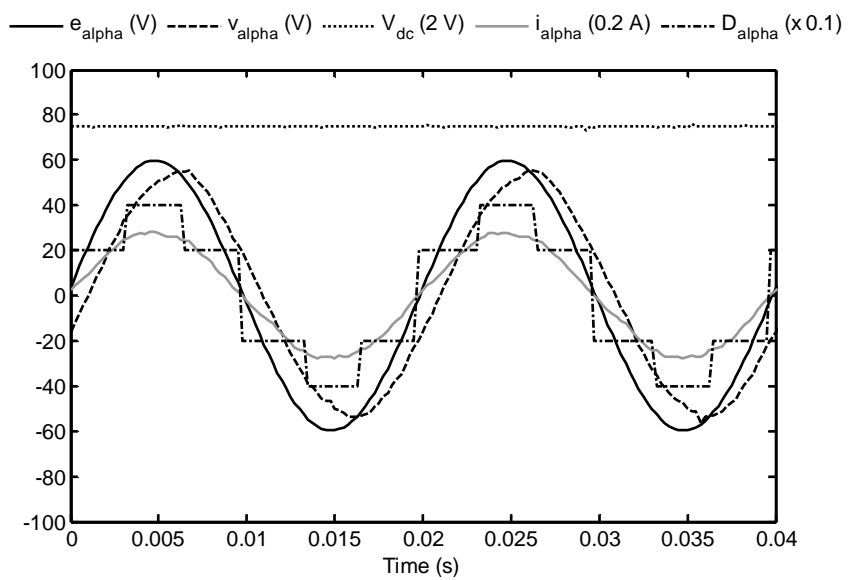

\subsection{Online identification results of $R, L$ and $V_{\text {dist }}$}

The proposed ADALINE technique for online identification of $R$ and $L$ is experimented. The VSR is controlled to achieve UPF operation using the classical VOC strategy. The PI gains $K_{p c}$ and $K_{i c}$ are calculated using the rated values shown in Table 1 . $V_{d c}$ is regulated to $150 \mathrm{~V}$ and $R_{L}$ is selected to $56 \Omega$. Several experiments have been realized. First test consists to verify stability and accuracy of the identification method in steady state conditions. Second test is performed to show the effect of VSR nonlinearity in $R$ and $L$ identification. Two last tests are realized to show tracking ability of the identification algorithm with respect to step changes in $L$ and $R$. In this paper, $V_{\text {dist }}$ is identified to verify the good convergence of the ADALINE weights.

Figure 10 Steady state performances of the ADALINE identifier: (a) estimation error, (b) identified $R$, (c) identified $L$ and (d) identified $V_{\text {dist }}$

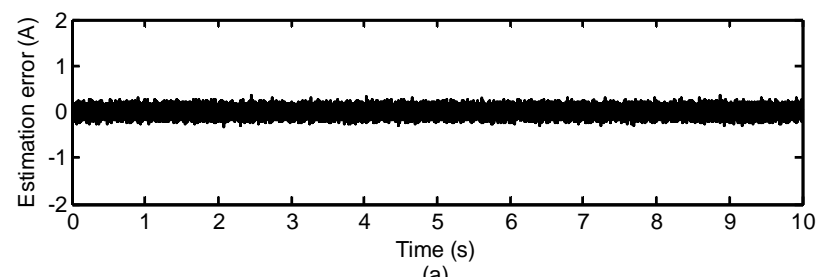

(a)
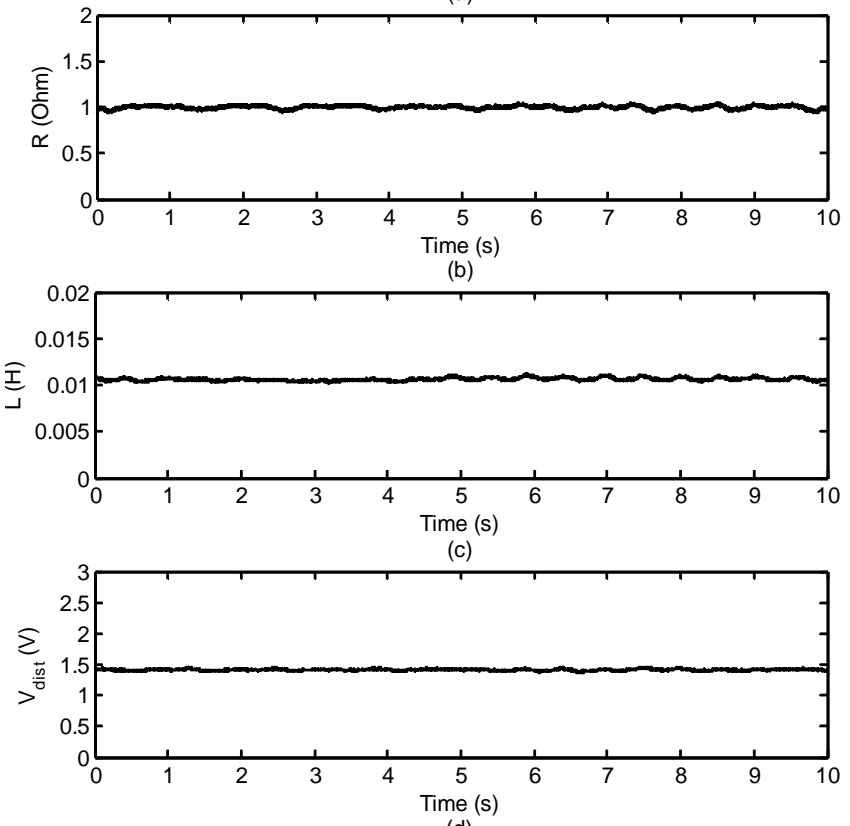

(d)

As analyzed in Section 4.1, identification of $R, L$ and $V_{\text {dist }}$ consists of implementing (37). This method uses $Z_{\alpha}(k-1)$, $i_{\alpha}(k-1)$ and $D_{\alpha}(k-1)$ as inputs in order to estimate $i_{\alpha}(k)$. The estimation error $\delta_{\alpha}(k)$ is used in (37) for online updating $\mathrm{W}_{1}$, $\mathrm{W}_{2}$ and $\mathrm{W}_{3}$. Therefore, these weights are exploited using (36) to reconstitute in real time $R, L$ and $V_{\text {dist }}$ values. Figure 9 shows the used signals in identification process. From this, it can be observed that the VSR operates at UPF since $e_{\alpha}$ and $i_{\alpha}$ are in phase, $D_{\alpha}$ has the six-step waveform and peaks of \pm 4 , and $V_{d c}$ is well regulated to $150 \mathrm{~V}$. Figure 10 illustrates the steady state performances of the proposed identification method. As shown in Figure 10(a), the ADALINE operates properly with good accuracy since $\delta_{a}$ is very small. This proves the stability of the ADALINE identifier. Figures 10(b)-(d) show, respectively, the identified $R, L$ and $V_{\text {dist }}$ values. According to these results, the ADALINE remain stable, since the identified parameters converge to stable and constant values. The identified $R$ value is $1.01 \Omega$ and the 
identified $L$ value is $10.45 \mathrm{mH}$. Therefore, the identified values are very close to the nominal values provided in Table 1. The identified value of $V_{\text {dist }}$ is also stable and close to $1.45 \mathrm{~V}$. On the other hand, the calculated typical value of $V_{\text {dist }}$ from Table 2 (from the Mitsubishi official datasheet) is $1.4 \mathrm{~V}$. Hence, the identified $V_{\text {dist }}$ value stays realistic since it is close the typical one.

Figure 11 Influence of VSR nonlinearity on $R$ and $L$ identification values: (a) identified $R$ and (b) identified $L$

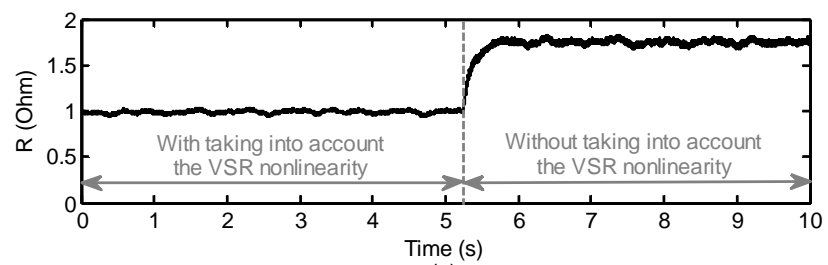

(a)

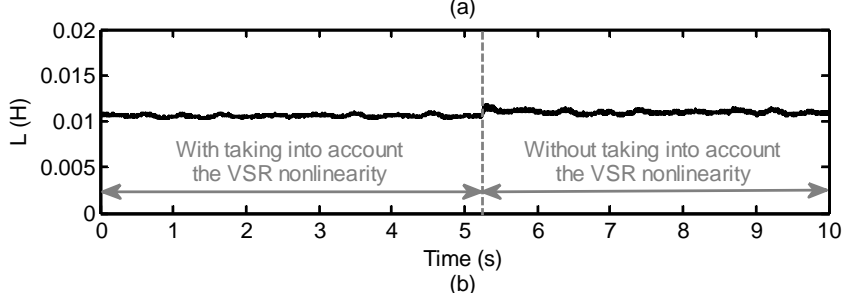

(b)

To study the influence of the VSR nonlinearity in $R$ and $L$ identification, tests with and without taking into account the VSR nonlinearity in the ADALINE structure are performed. The test without taking into account the VSR nonlinearity consists of implementing (37) with only two weights $\mathrm{W}_{1}$ and $\mathrm{W}_{2}$, i.e., the input of $\mathrm{W}_{3}$ is $D_{\alpha}(k-1)=0$ (see Figure 6). Figure 11 illustrates the obtained experimental results. In Figure 11(a), it can be seen that the effect of the VSR nonlinearity in $R$ identification is important. With taking into consideration the VSR nonlinearity the identified $R$ is $1.01 \Omega$, and without taking into consideration the VSR nonlinearity, the identified $R$ value passes to $1.76 \Omega$. Figure 11(b) shows the influence of the VSR nonlinearity in $L$ identification. Without taking into account the VSR nonlinearity, the identified $L$ value passes to $11.07 \mathrm{mH}$. Compared to the results shown in Figure 11(a), the influence of the VSR nonlinearity in $L$ identification is negligible. Consequently, the ADALINE interprets the VSR nonlinearity as an increased value in $R$.

Thereafter, two tests have been performed for illustrating the performances of the ADALINE identifier with respect to parameter variations.

Figure 12 presents the identified $R, L$ and $V_{\text {dist }}$ in case of step change in $L$. At time $t=3.47 \mathrm{~s}$, a three-phase inductance of $4.9 \mathrm{mH}$ has been connected in series with the ac filter. In Figure 12 (b), $L$ is identified within 0.09 s after step change in $L$. The identified $L$ value is close to $15.35 \mathrm{mH}$. A slight deviation in $R$ value is appeared and stabilized at $1 \Omega$ within 0.09 s (Figure 12(a)). Figure 12(c) shows a slight deviation of $V_{\text {dist }}$ from its initial value and is stabilized within $0.09 \mathrm{~s}$. Figure 13 presents the identified $R, L$ and $V_{\text {dist }}$ in case of step change in $R$. At time $t=3.34 \mathrm{~s}$, a three-phase resistance of $0.4 \Omega$ has been short-circuited in the interconnected resistances (see Figure 8). In Figure 13(a), $R$ is identified within 0.09 s after step change in $R$. The identified $R$ value is close to $0.61 \Omega$. In Figure 13(b), the identified $L$ value remains stable (about $10.45 \mathrm{mH}$ ) and it seems not affected by $R$ variation. Figure 13(c) shows a slight deviation of $V_{\text {dist }}$ but it tends to converge to its initial value.

Figure 12 Performances of the proposed method for step change in $L$

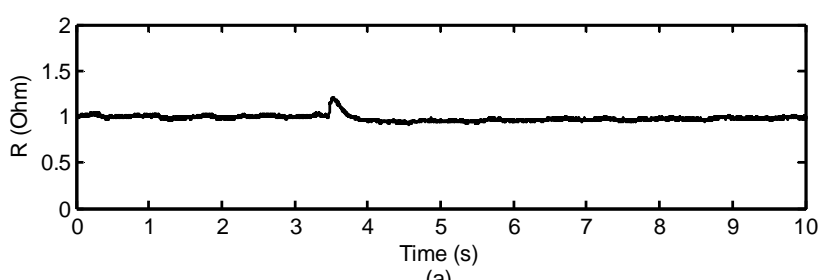

(a)
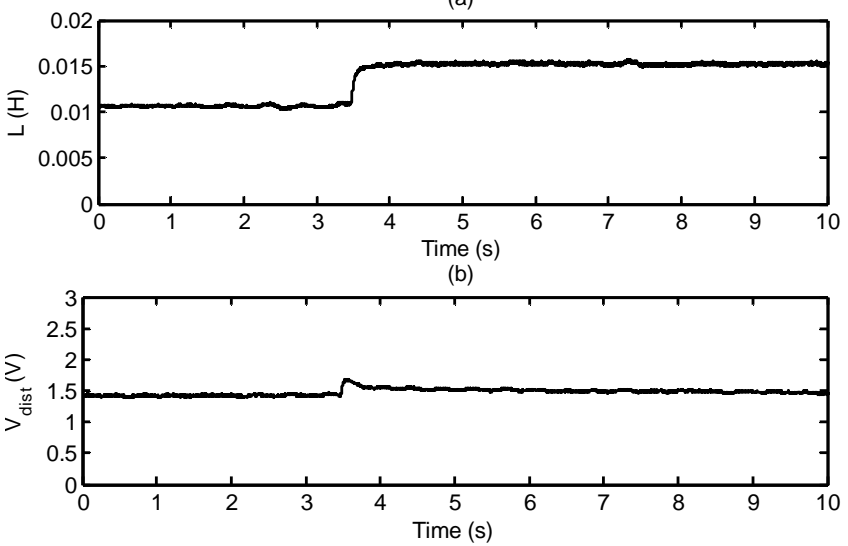

(c)

Figure 13 Performances of the proposed method for step change in $R$
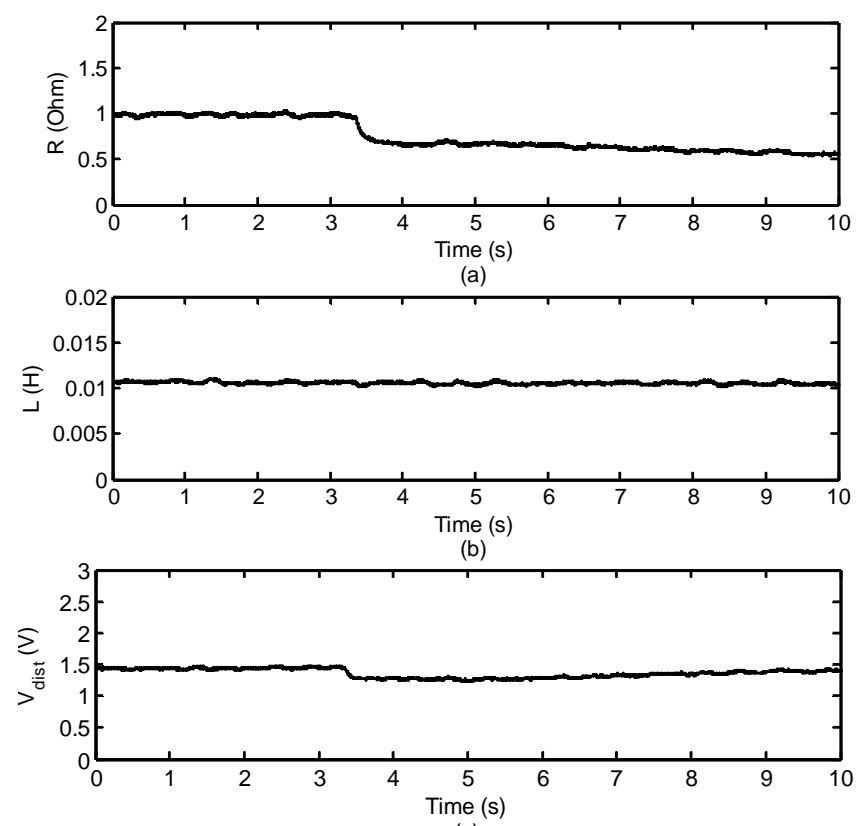

(c)

Figures 10-13 reveal that the ADALINE identifier guarantees precise identification. Therefore, the identified parameters can be reliably used in different control blocks of VOC strategy. 


\subsection{Classical VOC of VSR with parameter uncertainties}

As has been seen in Section 2.2, VOC requires knowledge of $R$ and $L$ for $K_{p c}$ and $K_{i c}$ computation. The terms $L \omega i_{q}$ and $L \omega i_{d}$ are needed for decoupling $i_{d}$ and $i_{q}$ dynamics, respectively. Hence, any deviation of $R$ and $L$ from their nominal values affects the control performances.

Figure 14 Performances of the classical VOC of a VSR with $60 \%$ mismatch in both $R$ and $L$ : (a) dc voltage $V_{d c}$, (b) $d$-axis current $i_{d}$, (c) $q$-axis current $i_{q}$, (d) $d$-axis modulation signal $\beta_{d}$ and (e) $q$-axis modulation signal $\beta_{q}$

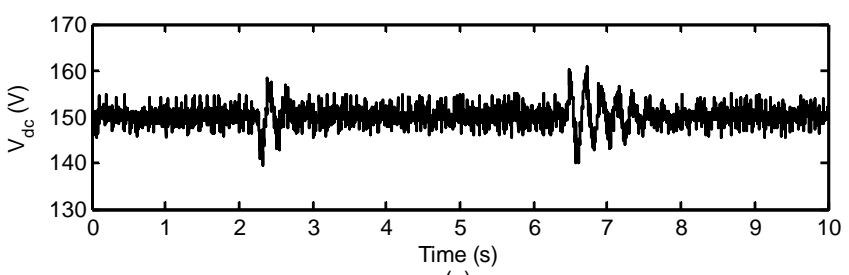

(a)

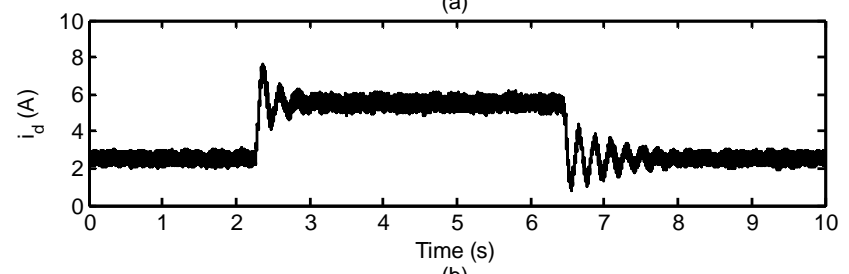

(b)

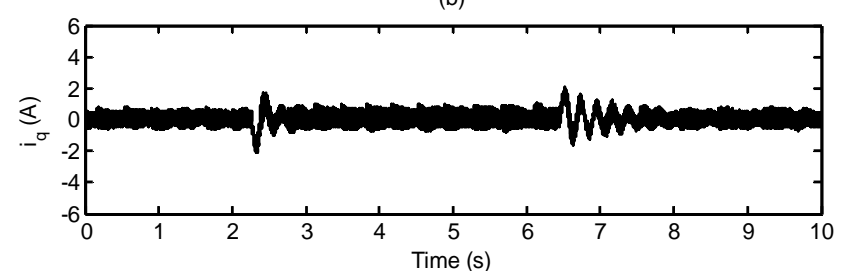

(c)

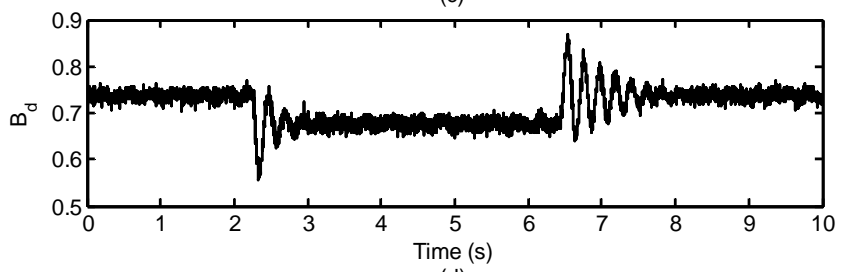

(d)

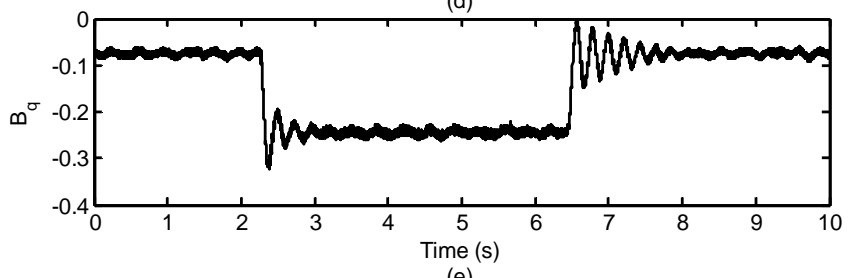

(e)

This subsection presents the performances of the classical VOC of VSR with $60 \%$ mismatch in both $R$ and $L$. The dc voltage is regulated to $150 \mathrm{~V}$. The load resistance $R_{L}$ is varied from $110 \Omega$ to $55 \Omega$ at time $t_{1}=2.28 \mathrm{~s}$ and from $55 \Omega$ to $110 \Omega$ at time $t_{2}=6.45 \mathrm{~s}$. $i_{q}{ }^{*}$ is set to zero to ensure a UPF operation. The obtained results are illustrated in Figure 14. In Figure 14(a), oscillations in $V_{d c}$ are observed at times $t_{1}$ and $t_{2}$. As $L$ is mismatched, the terms $L \omega i_{q}$ and $L \omega i_{d}$ are not exactly calculated for $i_{d}$ and $i_{q}$ dynamics decoupling. In addition, the computed gains $K_{p c}$ and $K_{i c}$ cannot achieve the desired performances since the identified $R$ and $L$ are not exact. Figures 14(b) and (c) show that $i_{d}$ and $i_{q}$ are degraded and present oscillations at transient states. This degrades the power factor of the system since $i_{q}$ is not well maintained to zero. From Figures $14(\mathrm{~d})$ and (e), the modulation signals $\beta_{d}$ and $\beta_{q}$ present also oscillations in transient states and tends to be saturated.

Figure 15 Performances of the adaptive VOC of a VSR: (a) dc voltage $V_{d c}$, (b) $d$-axis current $i_{d}$, (c) $q$-axis current $i_{q}$, (d) $d$-axis modulation signal $\beta_{d}$ and (e) $q$-axis modulation signal $\beta_{q}$

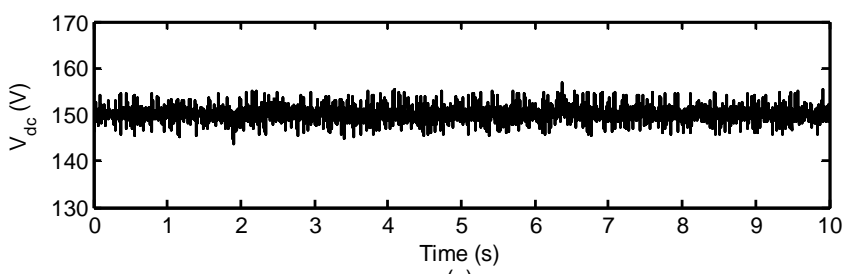

(a)
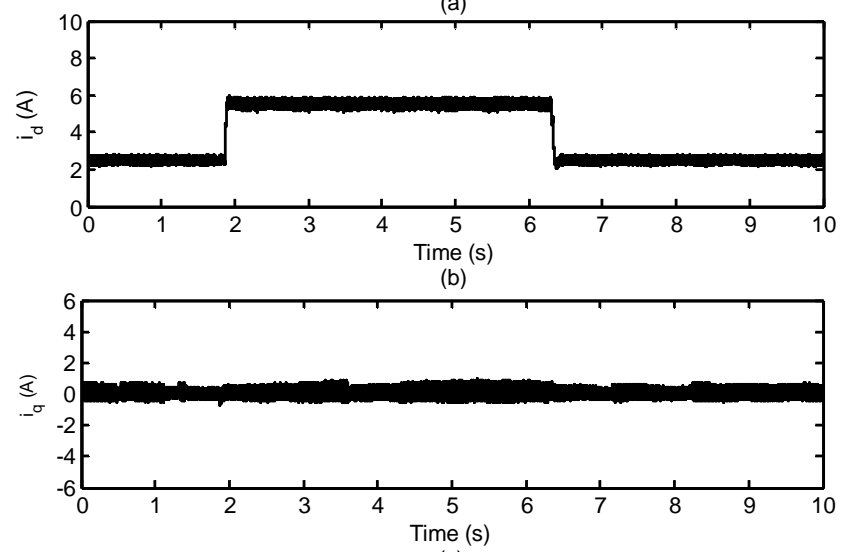

(c)

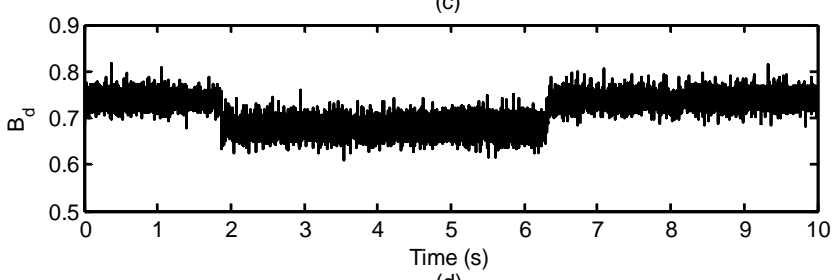

(d)

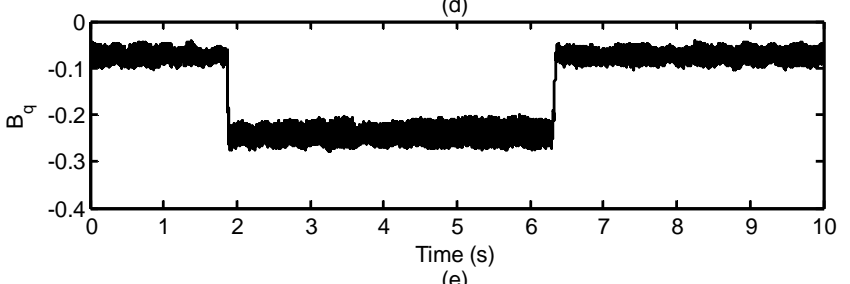

(e)

Although the integral term in PI controller compensates the steady state error, oscillations in transient states are appeared. These degrade the power factor and can driven the system into instability. To improve the classical VOC performances, the PI current controller gains and decoupling terms must be updated. The following subsection presents the validation results of the proposed scheme, reported in Figure 7 , for adaptive VOC. 


\subsection{Adaptive VOC of three-phase VSR}

As shown in Figure 15, the adaptive VOC achieves good performances in transient and steady states with respect to $R_{L}$ variation. The dc voltage is regulated to $150 \mathrm{~V}$. The load resistance $R_{L}$ is varied from $110 \Omega$ to $55 \Omega$ at time $t_{1}=1.87 \mathrm{~s}$ and from $55 \Omega$ to $110 \Omega$ at time $t_{2}=6.31 \mathrm{~s}$. $i_{q}{ }^{*}$ is set to zero to ensure a UPF operation. In Figure 15(a), transient performance of the regulated $V_{d c}$ is fast and zero steady state error is achieved. From Figures 15(b)-(e), the proposed adaptive VOC is more stable since the oscillations in transient states are removed. Indeed, the proposed adaptive control method can stay stable at any values of $R$ and $L$. This is due to the self tuning feature, which enables the redesign of PI gains and decoupling terms in real time at different parameters. Therefore, in the proposed adaptive PI current controllers, the stability of VOC strategy becomes independent of system parameters.

The reported results indicate that the proposed adaptive scheme results in stable and robust grid-connected VSR operation and favorable dc voltage regulation response.

\section{Conclusion}

In this paper, an adaptive VOC of a VSR with ac filter parameters identification method was introduced. The proposed identification method, based on ADALINE, is robust and requires low computational cost. The VSR nonlinearity has been analyzed and included in the ADALINE structure. Hence, accurate ac filter parameters have been easily obtained from the ADALINE weights. Thereafter, the identified parameters have been used to realize an adaptive VOC where the decoupled terms and PI current controller gains have been updated online. Finally, the obtained experimental results have proved the ADALINE ability to track with accuracy the $R$ and $L$ values. It has been observed that the VSR nonlinearity consideration has significant influence on the identification of $R$ value and has negligible influence on the identification of $L$ value. A comparative study has showed the superiority of the proposed adaptive VOC scheme compared to the classical one under parameter uncertainties. The developed ADALINE identifier is independent on the type of the VSR control; therefore; it can be used to enhance the robustness of further existing control methods.

\section{References}

Rashid, M.H. (2003), Power Electronics - Circuits, Devices and Applications, 3rd Edn, Pearson, Prentice-Hall.

Kolar, J.W. and Friedli, T. (2013) 'The essence of three-phase PFC rectifier systems-Parte I', IEEE Transactions on Power Electronics, Vol. 28, No. 1, 176-198.

Friedli, T., Hartmann, M. and Kolar, J.W. (2014) 'The essence of three-phase PFC rectifier systems-Parte II', IEEE Transactions on Power Electronics, Vol. 29, No. 2, pp. 543560.

Milasi, R.M., Lynch, A.F. and Li, Y.W. (2013) 'Adaptive vector control for voltage source converters', IET Control Theory and Applications, Vol. 7, No. 8, pp. 1110-1119.

Antoniewicz, P. and Kazmierkowski, M.P. (2008) 'Virtual-fluxbased predictive direct power control of ac/dc converters with online inductance estimation', IEEE Transactions on Industrial Electronics, Vol. 55, No. 12, pp. 4381-4390.

Schauder, C. and Mehta, H. (1993) 'Vector analysis and control of advanced static VAR compensators', IEE Proceedings- $C$, Vol. 140, No. 4, pp. 299-306.

Malinowski, M., Kazmierkowski, M.P. and Trzynadlowski, A.M. (2003) 'A comparative study of control techniques for PWM rectifiers in ac adjustable speed drives', IEEE Transactions on Power Electronics, Vol. 18, No. 6, pp. 1390-1396.

Shaker, H.R. (2014) 'Stability analysis and output feedback control for a class of switched nonlinear systems', International Journal of Modelling, Identification and Control, Vol. 22, No. 4, pp. 328-333.

Yan, X-G., Zhang, Q., Spurgeon, S.K., Zhu, Q. and Fridman, L.M. (2014) 'Decentralised control for complex systems - an invited survey', International Journal of Modelling, Identification and Control, Vol. 22, No. 4, pp. 285-297.

Zhang, Y., Xie, W., Li, Z. and Zhang, Y. (2013) 'Model predictive direct power control of a PWM rectifier with duty cycle optimization', IEEE Transactions on Power Electronics, Vol. 28, No. 11, pp. 5343-5351.

Norniella, J.G., Cano, J. M., Orcajo, G.A., Garcia, C., Pedrayes, J.F., Cabanas, M. F. and Melero, M.G. (2011) 'Analytic and iterative algorithms for online estimation of coupling inductance in direct power control of three-phase active rectifiers', IEEE Transactions on Power Electronics, Vol. 26, No. 11, pp. 3298-3307.

Kwak, S., Moon, U.C. and Park, J.C. (2014) 'Predictive-controlbased direct power control with an adaptive parameter identification technique for improved AFE performance', IEEE Transactions on Power Electronics, Vol. 29, No. 11, pp. 6178-6187.

Xia, C., Wang, M., Song, Z. and Liu, T. (2012) 'Robust model predictive current control of three-phase voltage source PWM rectifier with online disturbance observation', IEEE Transactions on Industrial Informatics, Vol. 8, No. 3, pp. 459-471.

Ramirez, R.O., Espinoza, J.R., Villarroel, F., Maurelia, E. and Reyes, M.E. (2014) 'A novel hybrid finite control set model predictive control scheme with reduced switching', IEEE Transactions on Industrial Electronics, Vol. 61, No. 11, pp. $5912-5920$.

Korelic, J. and Jezernik, K. (2013) 'Predictive variable-structure system control of unity power factor rectifiers', IET Power Electronics, Vol. 6, No. 8, pp. 1608-1617.

Gensior, A., Sira-Ramirez, H. and Guldner, H. (2009) 'On some nonlinear current controllers for three-phase boost rectifiers', IEEE Transactions on Industrial Electronics, Vol. 56, No. 2, pp. 360-370.

Burgos, R.P., Wiechmann, E.P. and Holtz, J. (2005) 'Complex state-space modeling and nonlinear control of active front-end converters', IEEE Transactions on Industrial Electronics, Vol. 52, No. 2, pp. 363-377.

Arriagada, A.J., Espinoza, J.R., Rodriguez, J.R. and Moran, L.A. (2003) 'On-line filtering reactance identification in voltagesource three-phase active-front-end rectifiers', in IECON2003: Proceedings of the IEEE Industrial Electronics Conference, Vol. 1, pp. 192-197. 
Liu, K., Zhu, Z.Q., Zhang, Q. and Zhang, J. (2012) 'Influence of nonideal voltage measurement on parameter estimation in permanent-magnet synchronous machines', IEEE Transactions on Industrial Electronics, Vol. 59, No. 6, pp. $2438-2447$.

Choi, J.W. and Sul, S.K. (1996) 'Inverter output voltage synthesis using novel dead time compensation', IEEE Transactions on Power Electronics, Vol. 11, No. 2, pp. 221-227.

Kim, H.W., Youn, M.J., Cho, K.Y. and Kim, H.S. (2006) 'Nonlinearity estimation and compensation of PWM VSI for PMSM under resistance and flux linkage uncertainty', IEEE Transactions on Control Systems Technology, Vol. 14, No. 4, pp. 589-601.

Liu, K. and Zhu, Z.Q. (2014) 'Online estimation of the rotor flux linkage and voltage-source inverter nonlinearity in permanent magnet synchronous machine drives', IEEE Transactions on Power Electronics, Vol. 29, No. 1, pp. 418-427.
Bechouche, A., Sediki, H., Ould Abdeslam, D. and Haddad, S. (2012) 'A novel method for identifying parameters of induction motors at standstill using ADALINE', IEEE Transactions on Energy Conversion, Vol. 27, No. 1, pp. 105116.

Bechouche, A., Ould Abdeslam, D., Otmane-Cherif, T. and Seddiki, H. (2014) 'Adaptive neural PLL for grid-connected DFIG synchronization', Journal of Power Electronics, Vol. 14, No. 3, pp. 608-620.

Du, Z., Li, X. and Mao, Q. (2015) 'A new online hybrid learning algorithm of adaptive neural fuzzy inference system for fault prediction', International Journal of Modelling, Identification and Control, Vol. 23, No. 1, pp. 68-76.

Romdhane, H., Dehri, K. and Nouri, A.S. (2014) 'Stability analysis of discrete input output second order sliding mode control', International Journal of Modelling, Identification and Control, Vol. 22, No. 2, pp. 159-169. 